\title{
Developing Empirical Models for Estimating Photo synthetically Active Radiation overAkure, South Western, Nigeria
}

\author{
D. O. Akpootu ${ }^{1}$, M. I. Iliyasu' ${ }^{2}$, M. B. Abubakar ${ }^{2}$, A. M. Rabiu ${ }^{3}$, W. Mustapha ${ }^{4}$, C. F. Okany ${ }^{5}$ and S. I. Salifu ${ }^{6}$ \\ ${ }^{1}$ Department of Physics, Usmanu Danfodiyo University, Sokoto, Nigeria \\ ${ }^{2}$ Physics Unit, Umaru Ali Shinkafi Polytechnic, Sokoto State, Nigeria \\ ${ }^{3}$ Sokoto Energy Research Centre, Usmanu Danfodiyo University, Sokoto, Nigeria \\ ${ }^{4}$ Nigerian Meteorological Agency (NIMET), Abuja, Nigeria \\ ${ }^{5}$ Research Scholar, Department of Physics, Usmanu Danfodiyo University, Sokoto, Nigeria \\ ${ }^{6}$ Department of Physics, Kogi State College of Education Technical Kabba, Nigeria
}

\begin{abstract}
In this study, the measured monthly average daily global solar radiation and extraterrestrial solar radiation using the generalized $45 \%$ and $40 \%$ dataset was utilized to estimate the photosynthetically active radiation (PAR) and extraterrestrial photosynthetically active radiation $\left(\mathrm{PAR}_{0}\right.$ ) for Akure (Latitude $7.17^{\circ} \mathrm{N}$, Longitude $5.18^{\circ} \mathrm{E}$, and $375.0 \mathrm{~m}$ above sea level) Ondo State located in South Western, Nigeria. The monthly average daily sunshine hours, maximum and minimum temperature data were used to develop nine (9) new PAR sunshine based models and three (3) PAR temperature based models. The meteorological parameters used in this study covered a period of thirty one years $(1980-2010)$. The newly developed models were tested using statistical indicators of coefficient of determination $\left(\mathrm{R}^{2}\right)$, Mean Bias Error (MBE), Root Mean Square Error (RMSE), Mean Percentage Error (MPE), $t$ test, Nash - Sutcliffe Equation (NSE) and Index of Agreement (IA). The PAR sunshine based models that took a quadratic form and the linear logarithmic PAR temperature based models were found more suitable for estimating PAR for the location under study. Comparing the PAR sunshine based and temperature based models indicated that the PAR sunshine based model is more suitable for PAR estimation in Akure. Furthermore, the results showed that the PAR is high during the dry season and low during the rainy season. Based on the measured and estimated PAR models; the minimum values was found in July and August while the maximum values in February, March and November. The descriptive statistical analysis shows that the PAR and all the estimated sunshine based PAR data spread out more to the left of their mean value (negatively skewed). Similarly, they have negative kurtosis which indicates a relatively flat distribution and possibility of platykurtic distribution. The PAR and the PAR logarithmic temperature based model (equation 17a) data spread out more to the left of their mean value (negatively skewed), while the PAR linear exponent and linear temperature based models (equation $17 \mathrm{~b}$ and $17 \mathrm{c}$ ) data spread out more to the right of their mean value (positively skewed). The PAR and all the estimated PAR temperature based data have negative kurtosis which indicates a relatively flat distribution and possibility of platykurtic distribution.
\end{abstract}

Keywords: photo synthetically active (PAR), extraterrestrial photo synthetically active $\left(\mathrm{PAR}_{0}\right)$ statistical indicators, Akure, descriptive statistics.

\section{INTRODUCTION}

Solar radiation is the main source of the Earth's surface energy exchanges [1 - 3]. The portion with wavelengths ranging from 400 to $700 \mathrm{~nm}$ is the primary energy source of vegetation photosynthesis, known as photosynthetically active radiation (PAR). It is the quantity of light energy that can be obtained for photosynthesis to take place and are usually within the wavelength range of 400 to $700 \mathrm{~nm}$. PAR is also a measure of the photosynthetic photon flux density (PPFD), and is defined as the number of the incident 
photons per unit time per unit surface [4]. Plants ultimately needs PAR as an energy requirement to convert carbon (iv) oxide $\left(\mathrm{CO}_{2}\right)$ and water $\left(\mathrm{H}_{2} \mathrm{O}\right)$ through photosynthesis into glucose which is used to synthesize structural and metabolic energy needed for plant growth, development, respiration as well as stored vegetative products that result in plant biomass [5 - 6]. This can be seen in the process plants used in synthesizing their food as given by the chemical equation:

$$
6 \mathrm{CO}_{2(\text { liquid })}+12 \mathrm{H}_{2} \mathrm{O}_{(\text {liquid })}+\text { Photon } \rightarrow \mathrm{C}_{6} \mathrm{H}_{12} \mathrm{O}_{6(\text { aqueous })}+6 \mathrm{O}_{2(\text { gas })}+6 \mathrm{H}_{2} \mathrm{O}_{(\text {liquid })}
$$

where the light represents PAR wavelength range $(0.4-0.7 \mu \mathrm{m})$ that is best fit for photosynthesis to occur.

The incident PAR at the earth's surface is of importance for modeling ecosystems and climate change studies [7 - 10]. The data for PAR is paramount for precise modeling of biomass productivities for renewable energy applications. Photosynthetically Active Radiation (PAR) can be measured using silicon photovoltaic detector. This detector measures light within the wavelength range of 400 to $700 \mathrm{~nm}$. The PPFD of photosynthetically active radiation can be measured with most of the PAR sensors which can also be used to quantify PAR. This is the most popular type of light sensor among plant biologists, horticulturists, ecologists, and other environmental scientists. The number of measurement sites in most areas of the world is scarce. Consequently, PAR data from measurements are not sufficient for the demand of PAR users. To overcome this problem, PAR data need to be obtained from modeling approaches. One of these approaches is to use a ratio of PAR to broadband solar radiation to estimate PAR from more widely measured broadband radiation. Many authors have proposed the values of this ratio using PAR and broadband radiation data from different parts of the world [11 - 13]. PAR changes seasonally and varies depending on the latitude and time of day. Conditions that lower the quantity of PAR obtained by plants include anything that reduces sunlight, such as shading by trees, cloud cover, and buildings. Air pollution is also a factor that affects PAR through filtering out the amount of sunlight accessible to plants.

Application of PAR-to-global radiation ratio has an advantage in terms of the simplicity, but it can be effectively used only for the locations where broadband solar radiation data are available. Several researches have been carried out on studies that involved the relationship between PAR and global solar radiation $(\mathrm{H})$ for different locations and climates across the globe; these include [14 24] to mention but a few.

The purpose of this study is to develop and compare new sunshine and temperature based photosynthetically active radiation (PAR) models capable of estimating PAR for Akure, Nigeria. The models are validated using seven different statistical indicators to ascertain the most suitable model in each case. The recommended sunshine and temperature based PAR models were also compared. The descriptive statistical analysis was also carried out.

\section{STUDY AREA}

Akure is the capital of Ondo State (Figure 1), Nigeria and the major dominating town is the Akure South Local Government. It lies between longitude $5^{\circ} 06^{\mathrm{ec}} \mathrm{E}$ to $5^{\circ} 38^{\mathrm{ec}} \mathrm{E}$ and between latitude $7^{\circ} 07^{\mathrm{ee}} \mathrm{N}$ to $7^{\circ} 37^{\mathrm{ee}} \mathrm{N}$ in the Southwestern Nigeria [25]. It is bounded by Owo Local Government Area in the east, Akure North and Ifedore Local Government Areas in the north, IleOluji/Oke- Igbo Local Government Area in the west and Idanre Local Government Area in the south. The rapid growth of the city, particularly within the last 25 years, has made it one of the fastest growing metropolitan cities in the Southwestern Nigeria. Its population has more than tripled from 157,947 in 1990 to 500,000 in 2006 [26]. The climatic condition of Akure is similar to those of Southwestern Nigeria where the climate is influenced majorly by the rain-bearing southwest monsoon winds from the ocean and the dry northwest winds from the Sahara Desert. The city experiences a warm humid tropical climate, with basically two distinct seasons, the rainy and dry seasons. The rainy season lasts for about seven months, April to October while the dry season is from November to March. Akure and its surrounding areas experience a frequent annual rainfall of over $1500 \mathrm{~mm}$ with a short August break. The mean temperature is about $22^{\circ} \mathrm{C}$ during harmattan period (December to February) and $32^{\circ} \mathrm{C}$ in March. The vegetation is tropical rainforest and drained by River Ala and its tributaries [27 - 28]. 


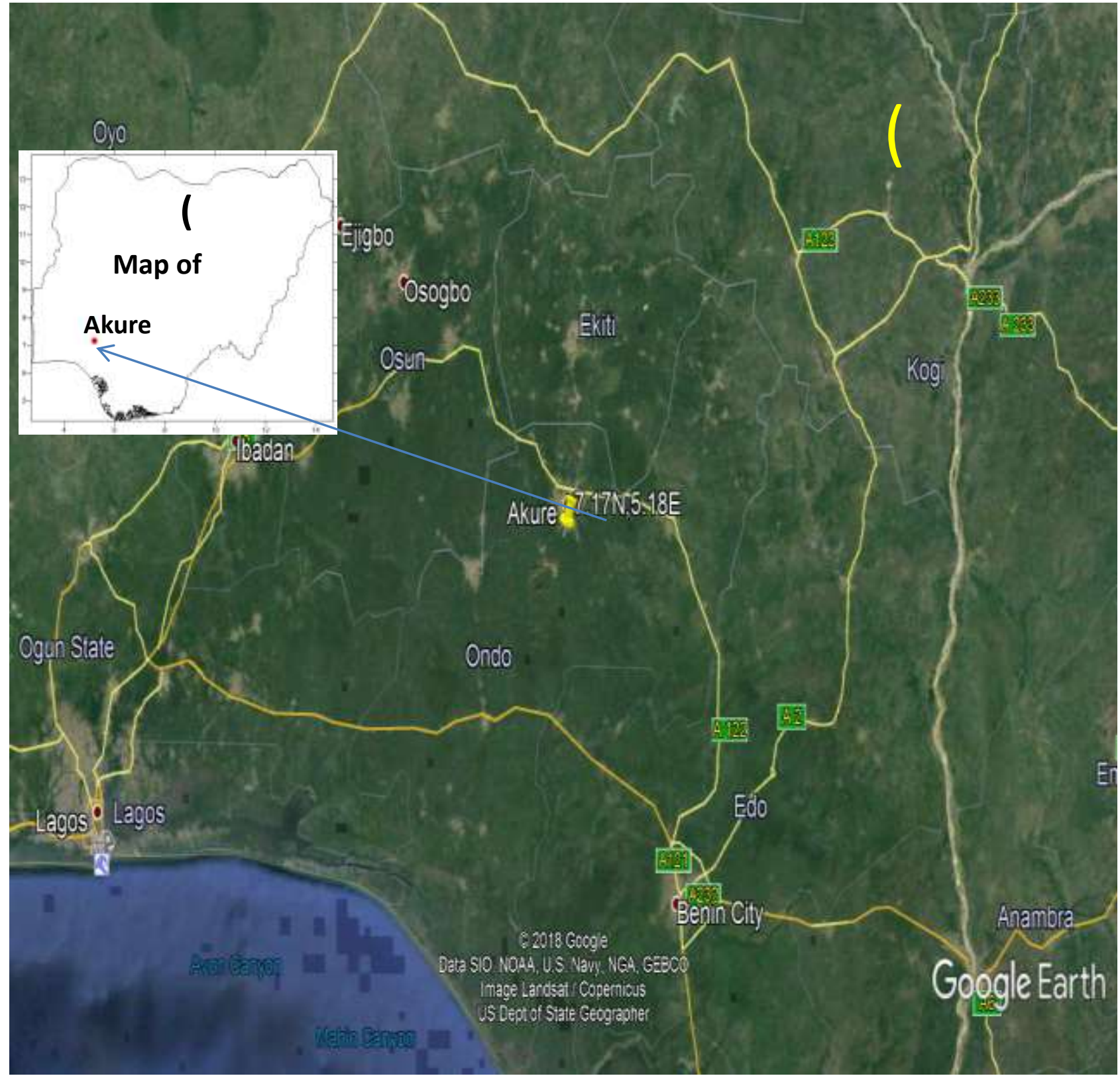

Figure 1. Map of (a) Google map showing the study area (b) Map of Nigeria showing the study area

\section{METHODOLOGY}

The measured monthly average daily global solar radiation, sunshine hours, maximum and minimum temperatures covering a period of thirty one years (1980-2010) for Akure, South - Western, Nigeria was obtained from the Nigeria Meteorological Agency (NIMET), Oshodi, Lagos, Nigeria.

The monthly average daily extraterrestrial radiation on a horizontal surface $\left(H_{o}\right)$ in $\mathrm{MJ} / \mathrm{m}^{2} / \mathrm{day}$, can be calculated for days giving average of each month from the following equation [29-30]:

$$
H_{o}=\left(\frac{24}{\pi}\right) I_{s c}\left[1+0.033 \cos \left(\frac{360 n}{365}\right)\right]\left[\cos \varphi \cos \delta \sin \omega_{s}+\left(\frac{2 \pi \omega_{s}}{360}\right) \sin \varphi \sin \delta\right]
$$

where $I_{s c}$ is the solar constant $\left(=1367 \mathrm{Wm}^{-2}\right), \varphi$ is the latitude of the site, $\delta$ is the solar declination and $\omega_{s}$ is the mean sunrise hour angle for the given month and $n$ is the number of days of the year starting from $1^{\text {st }}$ of January to $31^{\text {st }}$ of December.

The solar declination, $\delta$ and the mean sunrise hour angle, $\omega_{s}$ can be calculated using the following equation [29-30]:

$$
\delta=23.45 \sin \left\{360\left(\frac{284+n}{365}\right)\right\}
$$




$$
\omega_{s}=\cos ^{-1}(-\tan \varphi \tan \delta)
$$

For a given month, the maximum possible sunshine duration (monthly average day length $\left(S_{o}\right)$ ) can be computed [29 - 30] by

$$
S_{o}=\frac{2}{15} \omega_{S}
$$

Various measuring techniques and climatic parameters have been used in developing empirical models for estimating PAR. In this paper, the constant ratio of $45 \%$ of measured global solar radiation data as generalized by several researchers [14], [24], [31 $34]$ was used to obtain the $P A R$ data since there is no standard weather station that routinely measure $P A R$ in Nigeria and in particular Akure. Therefore, $P A R$ was obtained using

$$
P A R=0.45 H_{\text {mea }}
$$

where $H_{\text {mea }}$ is the measured global solar radiation in $\mathrm{MJ} / \mathrm{m}^{2} /$ day.

The extraterrestrial $P A R_{0}$ was estimated as $40 \%$ of the extraterrestrial global solar radiation as generalized by [35]. It was assumed that the sun-earth distance did not vary seasonally because the ratio of the distance between the earth and the sun on a specific day to the mean distance throughout the year is never more than $3.5 \%$ away from one [36]. Thus, extraterrestrial photo synthetically active radiation, $P A R_{0}$ was estimated using the expression

$$
P A R_{0}=0.4 H_{0}
$$

The $P A R$ and $P A R_{0}$ are in $\mathrm{MJ} / \mathrm{m}^{2} /$ day

The accuracy of the estimated values was tested by computing the Mean Bias Error (MBE), Root Mean Square Error (RMSE), Mean Percentage Error (MPE) and t-test. The expressions for the MBE, RMSE and MPE according to El-Sebaii and Trabea [37] are given by

$$
\begin{aligned}
& M B E=\frac{1}{n} \sum_{i=1}^{n}\left(P A R_{i, c a l}-P A R_{i, m e a}\right) \\
& R M S E=\left[\frac{1}{n} \sum_{i=1}^{n}\left(P A R_{i, c a l}-P A R_{i, m e a}\right)^{2}\right]^{\frac{1}{2}} \\
& M P E=\frac{1}{n} \sum_{i=1}^{n}\left(\frac{P A R_{i, m e a}-P A R_{i, c a l}}{P A R_{i, m e a}}\right) * 100
\end{aligned}
$$

The $\mathrm{t}$-test defined by student [38] in one of the tests for mean values, the random variable $\mathrm{t}$ with $\mathrm{n}-1$ degrees of freedom may be written as follows.

$$
t=\left[\frac{(n-1)(M B E)^{2}}{(R M S E)^{2}-(M B E)^{2}}\right]^{\frac{1}{2}}
$$

The Nash-Sutcliffe equation (NSE) is given by the expression

$$
N S E=1-\frac{\sum_{1}^{n}\left(\text { PAR }_{i, m e a}-P A R_{i, \text { cal }}\right)^{2}}{\sum_{1}^{n}\left(P A R_{i, m e a}-\overline{P A R}_{i, \text { meas }}\right)^{2}}
$$

The Index of Agreement (IA) is given as

$$
I A=1-\frac{\sum_{i=1}^{n}\left(P A R_{i, c a l}-P A R_{i, m e a}\right)^{2}}{\sum_{i=1}^{n}\left(\left|P A R_{i, c a l}-\overline{P A R}_{i, m e a}\right|+\left|P A R_{i, m e a}-\overline{P A R}_{i, m e a}\right|\right)^{2}}
$$

From equations (8) - (13) $P A R_{i, m e a}, P A R_{i, c a l}$ and $n$ are respectively the $i^{\text {th }}$ measured and $i^{\text {th }}$ calculated values of daily photo synthetically active radiation and the total number of observations. Iqbal [29] and Chen et al. [39] have recommended that a zero value for MBE is ideal and a low RMSE is desirable. Additionally, the smaller the value of the MBE, RMSE and MPE the better 
is the model's performance. The RMSE test provides information on the short-term performance of the studied model as it allows a term - by - term comparison of the actual deviation between the calculated values and the measured values. The MPE test gives long term performance of the examined regression equations, a positive MPE and MBE values provide the averages amount of overestimation in the calculated values, while the negative values gives underestimation. For a better model performance, a low value of MPE is desirable and the percentage error between $-10 \%$ and $+10 \%$ is considered acceptable [40]. The smaller the value of $t$ the better is the performance. To determine a model's statistical significant, one simply has to determine, from standard statistical tables, the critical $t$ value, i.e., $t \alpha / 2$ at $\alpha$ level of significance and $(n-1)$ degrees of freedom. For the model's estimates to be judged statistically significant at the $(1-\alpha)$ confidence level, the computed $t$ value must be less than the critical value. Similarly, for better data modelling, the coefficient of determination $R^{2}$ should approach 1 (100\%)as closely as possible [41 - 42]. MBE and RMSE are in MJ $/ \mathrm{m}^{2} / \mathrm{day}$, MPE, NSE and IA are in \% while $t-$ test is non-dimensional.

In this study, the skewness and kurtosis descriptive statistical tests analysis were also carried out. The skewness test $\left(\sigma_{k}\right)$ measures the asymmetry of the parameters data around their mean value; it is a measure of symmetry, or more precisely, the lack of symmetry [43]. It tells us about the direction of variation of the dataset [43]. If $\sigma_{k}=0$, the data have a Gaussian distribution (normal distribution), while $\sigma_{k}<0$ indicates that the data are spread out more to the left of the mean value than to its right (negatively skewed), when $\sigma_{k}>0$ indicates that data are spread out more to the right than to its left (positively skewed) [44]. The Kurtosis test $\left(k_{u}\right)$ describes the shape of a random variable's probability distribution, that is it characterizes the relative peakedness or flatness of a distribution compared to the normal distribution [43]. It measures the degree of normality of each of the meteorological parameters under investigation [44]. For $k_{u}=0$ the data have normal distribution, for $k_{u}>0$ the data have positive kurtosis which implies peaked distribution, that is, leptokurtic distribution (that is, too tall), when $k_{u}<0$ the data have negative kurtosis which implies flat distribution, that is, platykurtic distribution (that is, too flat, or even concave if the value is large enough).

The proposed sunshine $P A R$ based models developed in this study are of the forms:

$$
\begin{aligned}
& \frac{P A R}{P A R_{0}}=a+b\left(\frac{s}{s_{0}}\right) \\
& \frac{P A R}{P A R_{0}}=a+b\left(\frac{s}{s_{0}}\right)+c\left(\frac{s}{s_{0}}\right)^{2} \\
& \frac{P A R}{P A R_{0}}=a+b\left(\frac{s}{s_{0}}\right)+c\left(\frac{s}{s_{0}}\right)^{2}+d\left(\frac{s}{s_{0}}\right)^{3} \\
& \frac{P A R}{P A R_{0}}=a+b\left(\frac{s}{s_{0}}\right)+c \ln \left(\frac{s}{s_{0}}\right) \\
& \frac{P A R}{P A R_{0}}=a+b \ln \left(\frac{s}{s_{0}}\right) \\
& \frac{P A R}{P A R_{0}}=a+b\left(\frac{s}{s_{0}}\right)+c \exp \left(\frac{s}{s_{0}}\right) \\
& \frac{P A R}{P A R_{0}}=a+b \exp \left(\frac{s}{S_{0}}\right) \\
& \frac{P A R}{P A R_{0}}=a+b\left(\frac{s}{s_{n h}}\right) \\
& \frac{P A R}{P A R_{0}}=a\left(\frac{s}{s_{0}}\right)^{b}
\end{aligned}
$$

Model (14h) is a modification through the use of the ratio of $\left(\frac{s}{s_{n h}}\right)$ instead of $\left(\frac{s}{s_{0}}\right)$ and is given by the relation: $\frac{1}{s_{n h}}=\frac{0.8706}{S_{0}}+$ 0.0003

The proposed temperature $P A R$ based models developed in this study are of the forms:

$$
\begin{aligned}
& \frac{P A R}{P A R_{0}}=a_{2}+b_{2} \ln \Delta T \\
& \frac{P A R}{P A R_{0}}=a_{3}+b_{3} \Delta T^{0.5}
\end{aligned}
$$


International Journal of Advances in Scientific Research and Engineering (ijasre), Vol 5 (10), October-2019

$$
\frac{P A R}{P A R_{0}}=a_{4}+b_{4}\left(\frac{\Delta T}{S_{0}}\right)
$$

The constants $a, a_{2}, a_{3}, a_{4}, b, b_{2}, b_{3}$ and $b_{4}$ are PAR empirical constants, $\frac{s}{s_{0}}$ is the sunshine duration and $\Delta T$ is the difference between the monthly average daily maximum and minimum temperatures, i.e., $T_{\max }-T_{\min }$

\section{RESULTS AND DISCUSSION}

The evaluated sunshine PAR based models with their respective PAR empirical coefficients developed in this study are

$$
\begin{aligned}
& \frac{P A R}{P A R_{0}}=0.215+0.816\left(\frac{S}{S_{o}}\right) \\
& \frac{P A R}{P A R_{0}}=0.234+0.713\left(\frac{s}{s_{0}}\right)+0.129\left(\frac{s}{s_{0}}\right)^{2} \\
& \frac{P A R}{P A R_{0}}=-0.686+7.85\left(\frac{S}{S_{0}}\right)-17.5\left(\frac{s}{s_{0}}\right)^{2}+13.9\left(\frac{s}{S_{0}}\right)^{3} \\
& \frac{P A R}{P A R_{0}}=0.213+0.819\left(\frac{s}{s_{0}}\right)-0.001 \ln \left(\frac{s}{s_{0}}\right) \\
& \frac{P A R}{P A R_{0}}=0.840+0.313 \ln \left(\frac{S}{S_{0}}\right) \\
& \frac{P A R}{P A R_{0}}=0.035+0.52\left(\frac{S}{s_{0}}\right)+0.200 \exp \left(\frac{S}{s_{0}}\right) \\
& \frac{P A R}{P A R_{0}}=-0.274+0.544 \exp \left(\frac{S}{S_{0}}\right) \\
& \frac{P A R}{P A R_{0}}=0.215+0.934\left(\frac{s}{s_{n h}}\right) \\
& \frac{P A R}{P A R_{0}}=0.936\left(\frac{S}{S_{0}}\right)^{0.588}
\end{aligned}
$$

Table 1.Validation of the PAR sunshinme based models for Akure under different statistical test

\begin{tabular}{llllllll}
\hline Models & $\mathrm{R}^{2}$ & $\mathrm{MBE}$ & $\mathrm{RMSE}$ & $\mathrm{MPE}$ & $\mathrm{t}$ & $\mathrm{NSE}$ & $\mathrm{IA}$ \\
\hline Eqn16a & 95.7 & 0.0016 & 0.2467 & -0.0940 & 0.0214 & 99.9041 & 99.976 \\
Eqn16b & 95.8 & -0.0008 & 0.2465 & -0.0683 & 0.0107 & 99.9043 & 99.9761 \\
Eqn16c & 96.8 & -0.1437 & 0.2635 & 1.6555 & 2.1577 & 99.8906 & 99.9731 \\
Eqn16d & 95.7 & 0.0039 & 0.2468 & -0.1227 & 0.0528 & 99.9040 & 99.976 \\
Eqn16e & 94.8 & 0.0062 & 0.2703 & -0.1197 & 0.0763 & 99.8849 & 99.9712 \\
Eqn16f & 95.8 & 0.0252 & 0.2479 & -0.3912 & 0.3388 & 99.9031 & 99.9757 \\
Eqn16g & 95.7 & 0.0080 & 0.2489 & -0.1959 & 0.1064 & 99.9024 & 99.9756 \\
Eqn16h & 95.7 & 0.0046 & 0.2470 & -0.1313 & 0.0618 & 99.9039 & 99.9759 \\
Eqn16i & 95.7 & 0.0006 & 0.2514 & -0.0758 & 0.0085 & 99.9004 & 99.9751 \\
\hline
\end{tabular}

Table 2. Ranking of the evaluated PAR sunshine based models for Akure based on the Statistical test

\begin{tabular}{lllllllll}
\hline Models & $\mathrm{R}^{2}$ & $\mathrm{MBE}$ & $\mathrm{RMSE}$ & $\mathrm{MPE}$ & $\mathrm{t}$ & $\mathrm{NSE}$ & $\mathrm{IA}$ & Total \\
\hline Eqn16a & 3 & 3 & 2 & 3 & 3 & 2 & 2 & 18 \\
Eqn16b & 2 & 2 & 1 & 1 & 2 & 1 & 1 & 10 \\
Eqn16c & 1 & 9 & 8 & 9 & 9 & 8 & 7 & 51 \\
Eqn16d & 3 & 4 & 3 & 5 & 4 & 3 & 2 & 24
\end{tabular}


International Journal of Advances in Scientific Research and Engineering (ijasre), Vol 5 (10), October-2019

\begin{tabular}{lllllllll} 
Eqn16e & 4 & 6 & 9 & 4 & 6 & 9 & 8 & 46 \\
Eqn16f & 2 & 8 & 5 & 8 & 7 & 5 & 4 & 39 \\
Eqn16g & 3 & 7 & 6 & 7 & 8 & 6 & 5 & 42 \\
Eqn16h & 3 & 5 & 4 & 6 & 5 & 4 & 3 & 30 \\
Eqn16i & 3 & 1 & 7 & 2 & 1 & 7 & 6 & 27 \\
\hline
\end{tabular}

Table 1 gives the outline of the different statistical tests used and ranking of the PAR sunshine based models for Akure. Based on the $\mathrm{R}^{2}$ the model, equation $16 \mathrm{c}$ has the highest value with $96.8 \%$ and is judged the best model. Based on the MBE, the model, equation 16i has the lowest value with overestimation of $0.0006 \mathrm{MJm}^{-2} \mathrm{day}^{-1}$ in the estimated value and is judged the best model. Based on the RMSE the model, equation 16b has the lowest value with $0.2465 \mathrm{MJm}^{-2} \mathrm{day}^{-1}$ and is judged the best model. Based on the MPE, despite the observed overestimation and underestimation exhibited by the models, they all fall within the acceptable range $(M P E \leq \pm 10 \%)$ with the model, equation $16 \mathrm{~b}$ having the lowest value with underestimation of $0.0683 \%$ in the estimated value and is judged the best model. The study site was statistically tested at the $(1-\alpha)$ confidence levels of significance of $95 \%$ and 99\%. For the critical t-value, i.e., at $\alpha$ level of significance and degree of freedom, the calculated t-value must be less than the critical value $\left(t_{\text {critical }}=2.20, d f=11, p<0.05\right)$ for $95 \%$ and $\left(t_{\text {critical }}=3.12, d f=11, p<0.01\right)$ for $99 \%$. It was observed that the $t_{\text {cal }}<t_{\text {critical }}$ values for all the studied models. The $t$-test shows that all models are significant at $95 \%$ and $99 \%$ confidence levels. However, the model, equation 16i has the lowest value with 0.0085 and is judged the best model. Based on the NSE and IA the model, equation 16b has the highest values with $99.9043 \%$ and $99.9731 \%$ respectively and is judged the best model.

The ranking of the models (Table 2) was done based on the validation of the models (Table 1). The total ranks obtained by the different models ranged from 10 to 51 . Based on the overall results the model, equation $16 \mathrm{~b}$ was found the best and most suitable for estimating Photo synthetically Active Radiation (PAR) for the study area.

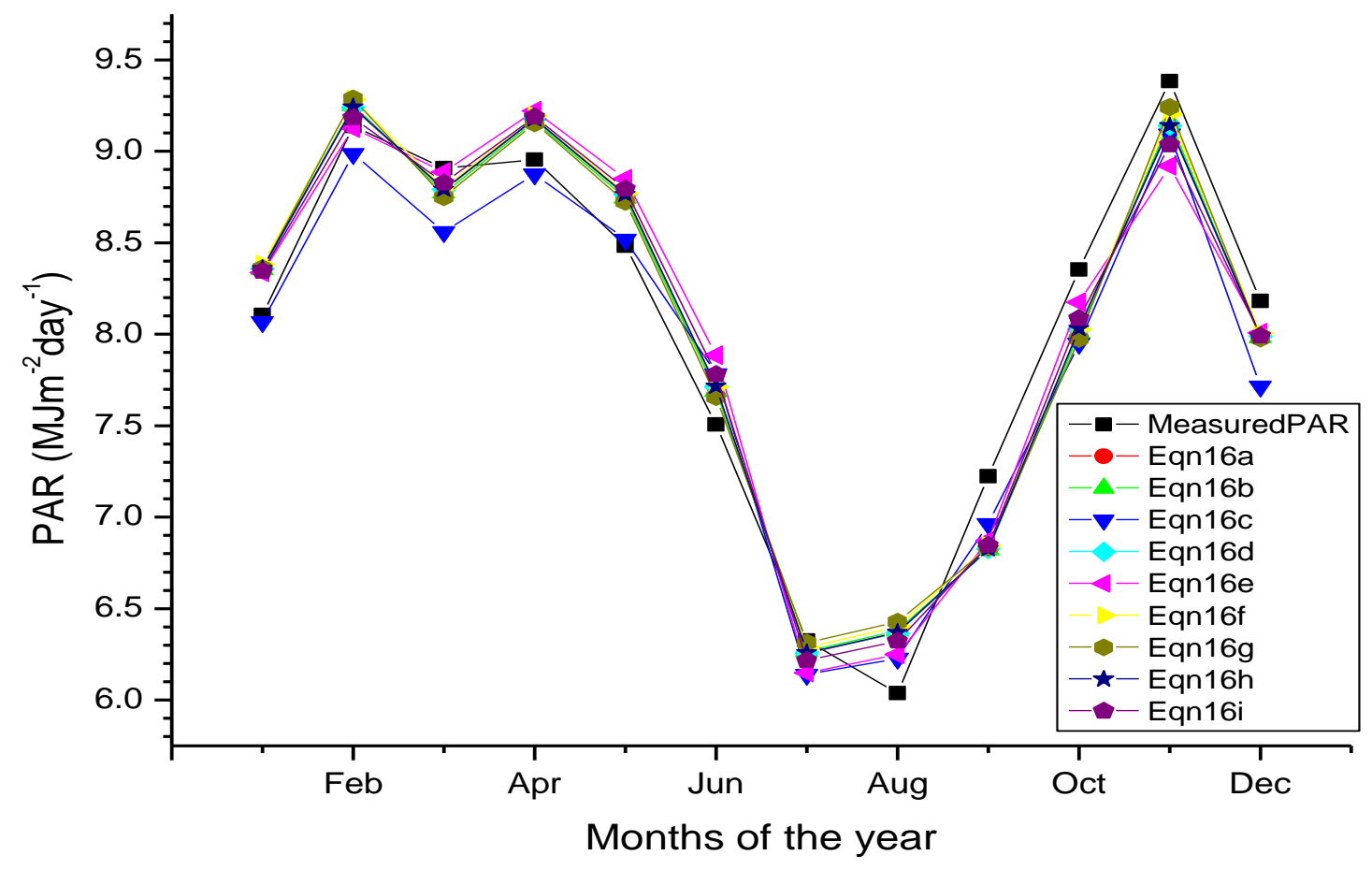

Figure 2. Comparison between the measured and estimated photosynthetically active radiation (PAR) sunshine based models for Akure

Figure 2 shows the comparison between the measured and estimated photosynthetically active radiation sunshine based models for Akure, South Western, Nigeria. The result showed that the minimum value of the monthly average daily PAR of $6.04 \mathrm{MJm}^{-2} \mathrm{day}^{-1}$ occurred in the month of August while for all the estimated PAR estimated sunshine based models occurred in 
the month of July; it is pertinent to note here that the months of July and August is during the rainy season for the location under investigation.The maximum measured PAR $\left(9.38 \mathrm{MJm}^{-2} \mathrm{day}^{-1}\right)$ and the model, equation $16 \mathrm{c}$ occurred in the month of November; this is expected as this the month when the harmattan dry season sets in. the maximum PAR for the model, equation 16e occurred in March while the estimated PAR models (equation 16a, 16b, 16d, 16f, 16g, 16h and 16i) occurred in the month of February. The measured PAR overestimated the estimated PAR sunshine based models in the months from September December and underestimated the estimated models in the months of May, June and August. The model, equation 16c underestimated the measured and other estimated models in the months from January - April and in December. The result further revealed that the values of the PAR are high during the dry season and low during the rainy season.

The evaluated temperature $P A R$ based models with their respective PAR empirical coefficients developed in this study are

$$
\begin{gathered}
\frac{P A R}{P A R_{0}}=-0.144+0.316 \ln \Delta T \\
\frac{P A R}{P A R_{0}}=-0.052+0.199 \Delta T^{0.5} \\
\frac{P A R}{P A R_{0}}=0.288+0.341\left(\frac{\Delta T}{S_{0}}\right)
\end{gathered}
$$

Table 3. Validation of the PAR temperature based models for Akure under different statistical test

\begin{tabular}{cccccccc}
\hline Models & $\mathrm{R}^{2}$ & $\mathrm{MBE}$ & $\mathrm{RMSE}$ & $\mathrm{MPE}$ & $\mathrm{t}$ & $\mathrm{NSE}$ & $\mathrm{IA}$ \\
\hline Eqn17a & 74.2 & 0.0111 & 0.5837 & -0.7278 & 0.0631 & 99.4631 & 99.865 \\
Eqn17b & 70.6 & -0.0178 & 0.626 & -0.4602 & 0.0943 & 99.3825 & 99.8452 \\
Eqn17c & 66.8 & -0.0023 & 0.6699 & -0.7795 & 0.0113 & 99.293 & 99.8223 \\
\hline
\end{tabular}

Table 4. Ranking of the evaluated PAR temperature based models for Akure based on the Statistical test

\begin{tabular}{lcccccccc}
\hline Models & $\mathrm{R}^{2}$ & $\mathrm{MBE}$ & $\mathrm{RMSE}$ & $\mathrm{MPE}$ & $\mathrm{t}$ & $\mathrm{NSE}$ & $\mathrm{IA}$ & Total \\
\hline Eqn17a & 1 & 2 & 1 & 2 & 2 & 1 & 1 & 10 \\
Eqn17b & 2 & 3 & 2 & 1 & 3 & 2 & 2 & 15 \\
Eqn17c & 3 & 1 & 3 & 3 & 1 & 3 & 3 & 17 \\
\hline
\end{tabular}

Table 3 presents the rundown of the various statistical tests implemented. Based on the $\mathrm{R}^{2}$ the model, equation 17a has the highest value with $74.2 \%$ and is judged the best model. Based on the MBE, the model, equation 17c has the lowest value with underestimation of $0.0023 \mathrm{MJm}^{-2} \mathrm{day}^{-1}$ in the estimated value and is judged the best model. Based on the RMSE the model, equation 17a has the lowest value with $0.5837 \mathrm{MJm}^{-2}$ day $^{-1}$ and is judged the best model. Based on the MPE, all the models fall within the acceptable range $(M P E \leq \pm 10 \%)$ with the model, equation $17 \mathrm{~b}$ having the lowest value with underestimation of $0.4602 \%$ in the estimated value and is judged the best model. Based on the $t-$ test the model, equation $17 \mathrm{c}$ was judged the best model. Based on the NSE and IA the model, equation 17a has the highest value with $99.4631 \%$ and $99.8650 \%$ respectively and is judged the best model.

The ranking of the models (Table 4) was done based on the validation of the models (Table 3). The total ranks obtained by the different models ranged from 10 to 18 . Based on the overall results the model, equation 17a was found the best and most suitable for estimating Photo synthetically Active Radiation (PAR) for the study area. 


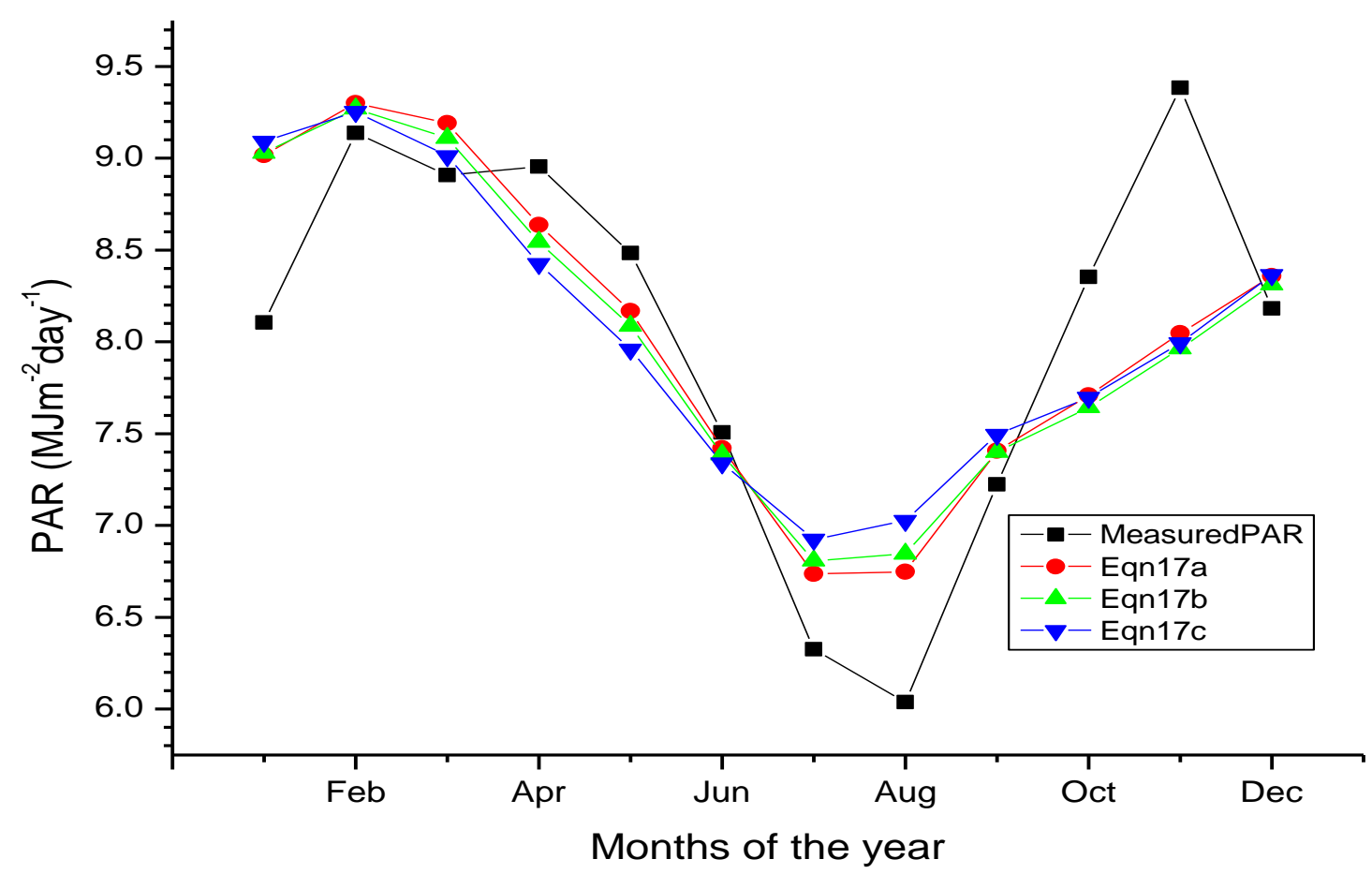

Figure 3. Comparison between the measured and estimated photosynthetically active radiation (PAR) temperature based models for Akure

Figure 3 shows the comparison between the measured and estimated photosynthetically active radiation temperature based models for Akure, South Western, Nigeria. The result showed that the minimum value of the monthly average daily PAR of $6.04 \mathrm{MJm}^{-2} \mathrm{day}^{-1}$ occurred in the month of August while for all the estimated PAR estimated temperature based models occurred in the month of July; it is pertinent to note here that the months of July and August is during the rainy season for the location under investigation. The minimum value of PAR found in this study is in line, though slightly higher than those reported in the study of Etuk et al [45] where they reported the minimum values of PAR to be in the range $\left(5.32-5.47 \mathrm{MJm}^{-2} \mathrm{day}^{-1}\right)$ for Calabar, Nigeria in the month of August. In this study the maximum measured PAR $\left(9.38 \mathrm{MJm}^{-2} \mathrm{day}^{-1}\right)$ occurred in the month of November; this is expected as this the month when the harmattan dry season sets in while all the estimated PAR temperature based models occurred in the month of February. The measured PAR overestimated the estimated PAR temperature based models in the months from April - June, October and November and underestimated the estimated models in the months of from January - March, July - September and in December. The model, equation 17c underestimated the measured and other estimated models in the months from April - June and overestimated the measured and other estimated models in the months of January and from July - September; similarly, the model, equation 17a overestimated the measured and other estimated models in the months from February - March. The result further revealed that the values of the PAR are high during the dry season and low during the rainy season. 


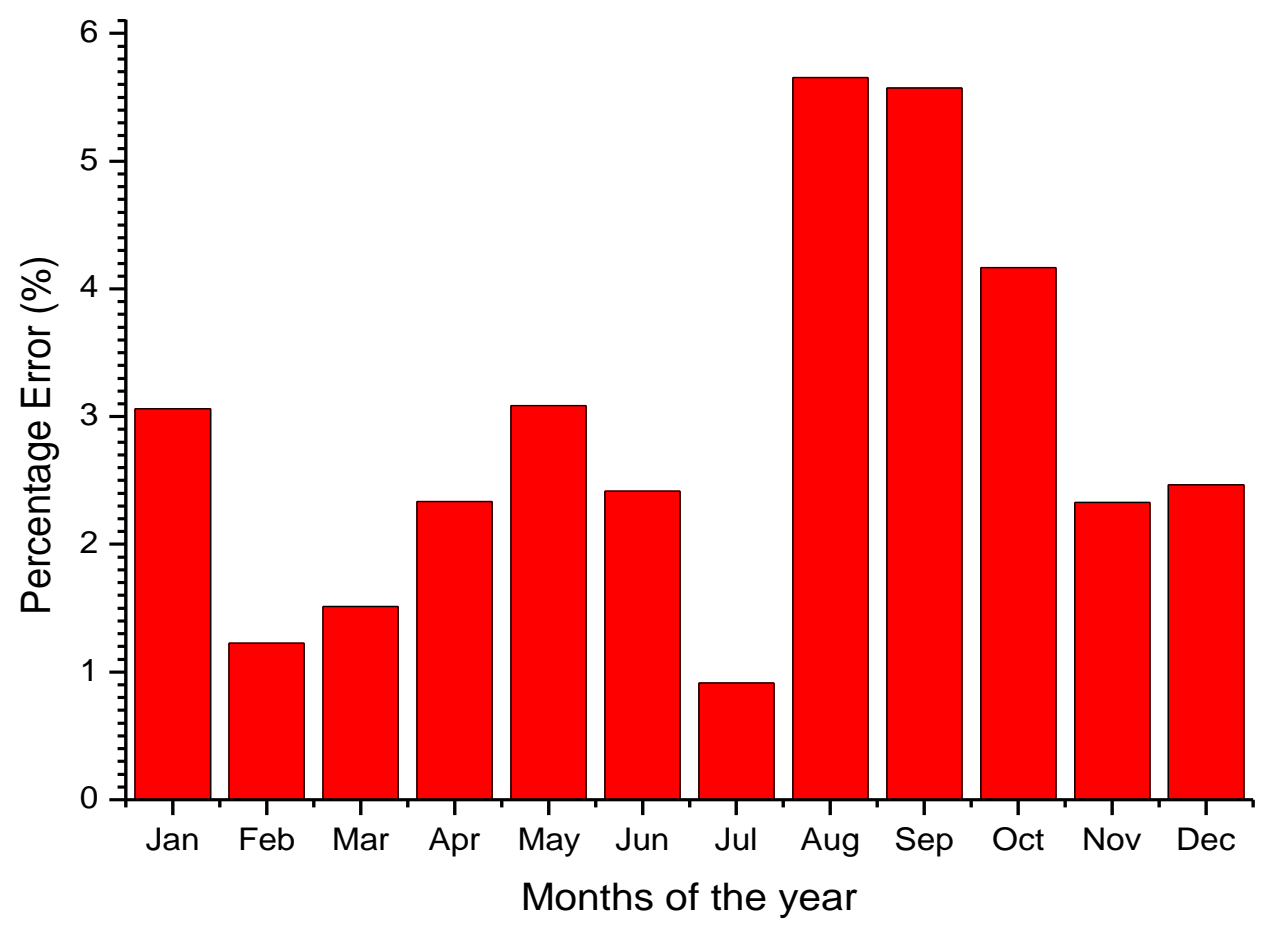

Figure 4. Monthly percentage error for the recommended PAR sunshine based models for Akure

Figure 4 shows the monthly percentage error for the recommended PAR sunshine based models for Akure. The percentage error ranged between $(0.92-5.66) \%$. The values are within the acceptable percentage error range of $\pm 10 \%$. The minimum percentage error of $0.92 \%$ occurred in the month of July and the maximum of $5.66 \%$ in the month of August. The implication of this result is that the model, equation $16 \mathrm{~b}$ is suitable for estimating PAR at any given time of the day in the year for the region under investigation provided the sunshine hour data is available with more accurate result in the month of July.

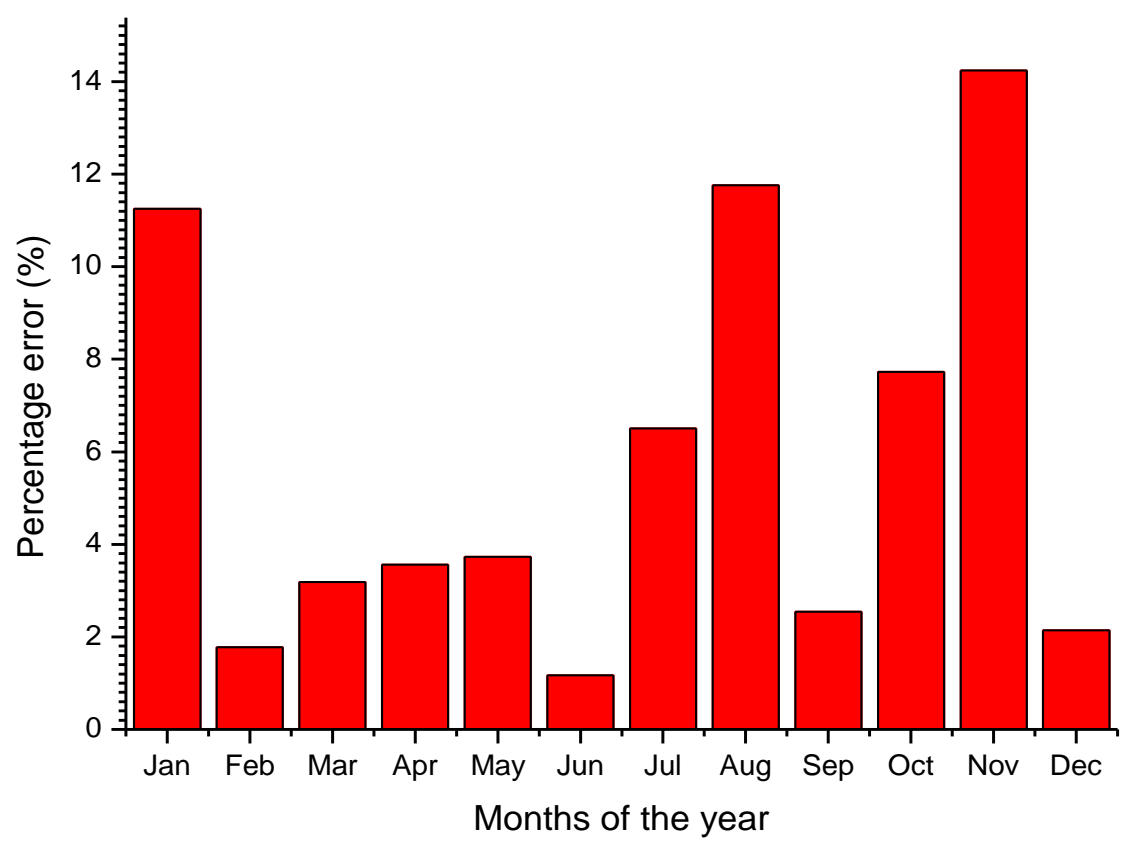

Figure 5. Monthly percentage error for the recommended PAR temperature based models for Akure 
Figure 5 shows the monthly percentage error for the recommended PAR temperature based models for Akure. The percentage error ranged between $(1.17-14.24) \%$. The values are within the acceptable percentage error range of $\pm 10 \%$ except in the months of January, August and November where the percentage error values are slightly high. The minimum percentage error of $1.17 \%$ occurred in the month of June and the maximum of $14.24 \%$ in the month of November. The implication of this result is that the model, equation 17a is suitable for estimating PAR at any given time of the day in the year for the region under investigation provided the minimum and maximum temperature hour data are available except in the months of January, August and November where it is slightly less accurate with more accurate result in the month of June.

Table 5. PAR and the estimated sunshine based descriptive statistical analysis for Akure, Nigeria

\begin{tabular}{ccccccc}
\hline & Range & Minimum & Maximum & Sum & Skewness & Kurtosis \\
& Statistic & Statistic & Statistic & Statistic & Statistic & Statistic \\
\hline PAR & 3.3468 & 6.0376 & 9.3843 & 96.6048 & -0.7690 & -0.3640 \\
Eqn16a & 2.9818 & 6.2556 & 9.2374 & 96.6239 & -0.6470 & -0.9150 \\
Eqn16b & 2.9828 & 6.2672 & 9.2501 & 96.5953 & -0.6180 & -0.9490 \\
Eqn16c & 2.9539 & 6.1403 & 9.0942 & 94.8805 & -0.7120 & -0.5490 \\
Eqn16d & 2.9833 & 6.2574 & 9.2407 & 96.6520 & -0.6470 & -0.9160 \\
Eqn16e & 3.0713 & 6.1499 & 9.2213 & 96.6794 & -0.8470 & -0.5950 \\
Eqn16f & 2.9943 & 6.2888 & 9.2831 & 96.9072 & -0.6130 & -0.9530 \\
Eqn16g & 2.9748 & 6.3128 & 9.2876 & 96.7006 & -0.5470 & -1.0170 \\
Eqn16h & 2.9828 & 6.2580 & 9.2407 & 96.6601 & -0.6470 & -0.9150 \\
Eqn16i & 2.9730 & 6.2167 & 9.1896 & 96.6126 & -0.7350 & -0.7910 \\
\hline
\end{tabular}

The results shown in Table 5 indicated that the PAR and all the estimated sunshine based PAR data spread out more to the left of their mean value (negatively skewed). Similarly, the PAR and all the estimated sunshine based PAR data have negative kurtosis which indicates a relatively flat distribution and possibility of platykurtic distribution. The range, minimum, maximum and sum exhibited by each model are displayed on the table. The average range is between $(2.9539-3.3468)$, the average minimum value $(6.0376-6.3128)$, the maximum value $(9.0942-9.3843)$. The model with the highest sum of value is equation $16 \mathrm{f}$ with $96.9072 \mathrm{MJm}^{-2} \mathrm{day}^{-1}$ while the lowest is equation $16 \mathrm{c}$ with $94.8805 \mathrm{MJm}^{-2} \mathrm{day}^{-1}$ for the period under study.

Table 6. PAR and the estimated temperature based descriptive statistical analysis for Akure, Nigeria

\begin{tabular}{lcccccc}
\hline & Range & Minimum & Maximum & Sum & Skewness & Kurtosis \\
& Statistic & Statistic & Statistic & Statistic & Statistic & Statistic \\
\hline PAR & 3.3468 & 6.0376 & 9.3843 & 96.6048 & -0.7690 & -0.3640 \\
Eqn17a & 2.5637 & 6.7368 & 9.3004 & 96.7380 & -0.1180 & -1.1040 \\
Eqn17b & 2.4630 & 6.8074 & 9.2704 & 96.3913 & 0.0320 & -1.1840 \\
Eqn17c & 2.3291 & 6.9238 & 9.2530 & 96.5774 & 0.1740 & -1.1870 \\
\hline
\end{tabular}

The results shown in Table 6 indicated that the PAR and equation 17a data spread out more to the left of their mean value (negatively skewed), while equation $17 \mathrm{~b}$ and $17 \mathrm{c}$ data spread out more to the right of their mean value (positively skewed). Equation $17 \mathrm{~b}$ data seem to have a quassi-Gaussian distribution. Skewness of exactly zero is quite not likely for real world data [43]. The PAR and all the PAR estimated temperature based data have negative kurtosis which indicates a relatively flat distribution and possibility of platykurtic distribution. The range, minimum, maximum and sum exhibited by each model are displayed on the table. The average range is between $(2.3291-3.3468)$, the average minimum value $(6.0376-6.8074)$, the maximum value $(9.2530-9.3843)$. The model with the highest sum of value is equation $17 \mathrm{a}$ with $96.7380 \mathrm{MJm}^{-2} \mathrm{day}^{-1}$ while the lowest is equation $17 \mathrm{~b}$ with $96.3913 \mathrm{MJm}^{-2} \mathrm{day}^{-1}$ for the period under study. 
The proposed PAR sunshine and temperature based models recommended for estimating photosynthetically active radiation (PAR) for Akure, South Western, Nigeria; if global solar radiation data is not available are given by the expressions

$$
\begin{gathered}
\frac{P A R}{P A R_{0}}=0.234+0.713\left(\frac{s}{s_{0}}\right)+0.129\left(\frac{s}{s_{0}}\right)^{2} \text { and } \\
\frac{P A R}{P A R_{0}}=-0.144+0.316 \ln \Delta T
\end{gathered}
$$

Table 7.Ranking and Comparison between the recommended PAR Sunshine Based Models (SBM) and PAR Temperature

\begin{tabular}{|c|c|c|c|c|c|c|c|c|c|c|c|}
\hline Location & Models & Equation & $\mathbf{R}^{2}$ & MBE & RMSE & MPE & $\mathbf{t}$ & NSE & IA & Total & Best \\
\hline & PAR & & & & & & & & & & \\
\hline & SBM & E.16b & 1 & 1 & 1 & 1 & 1 & 1 & 1 & 7 & \\
\hline & PAR & & & & & & & & & & PAR \\
\hline Akure & TBM & E.17a & 2 & 2 & 2 & 2 & 2 & 2 & 2 & 14 & SBM \\
\hline
\end{tabular}
Based Models (TBM) for Sokoto

Table 7 shows that the PAR sunshine based model is more reliable as compared to the PAR temperature based model for estimating photosynthetically active radiation for the location. It is important to note here that the PAR temperature based model can be use if global solar radiation and sunshine hours data are not available for the location under investigation.

\section{CONCLUSION}

Photosynthetically Active Radiation (PAR) is necessary for photosynthesis to take place and for the growth and development of plants. Sufficient amount of PAR enhanced plant growth and proper monitoring of PAR is paramount to ensure plants are receiving sufficient light for this process. This study addresses the issue of estimating photosynthetically active radiation (PAR) for Akure (Latitude $7.17^{\circ} \mathrm{N}$, Longitude $5.18^{\circ} \mathrm{E}$, and $375.0 \mathrm{~m}$ above sea level), Ondo state located in the south western, Nigeria. The data used in this study were obtained from the Nigerian Meteorological Agency (NIMET), Oshodi, Lagos, Nigeria. The monthly average daily global solar radiation, sunshine hours, minimum and maximum temperatures during the period of thirty one years (1980 - 2010) were utilized in this study. In this present investigation, nine (9) new PAR sunshine based models and three (3) PAR temperature based models were developed and compared on the basis of statistical indicators of coefficient of determination $\left(\mathrm{R}^{2}\right)$, Mean Bias Error (MBE), Root Mean Square Error (RMSE), Mean Percentage Error (MPE), $t-$ test, Nash Sutcliffe Equation (NSE) and Index of Agreement (IA). The results indicated that the PAR sunshine based models that took a quadratic form was found more suitable for estimating PAR for the location with $\mathrm{R}^{2}=95.8 \%, \mathrm{MBE}=-0.0008 \mathrm{MJm}^{-2} \mathrm{day}^{-1} \mathrm{RMSE}$ $=0.2465 \mathrm{MJm}^{-2} \mathrm{day}^{-1} \mathrm{MPE}=-0.0683 \mathrm{MJm}^{-2} \mathrm{day}^{-1}, \mathrm{t}-$ test $=0.0107, \mathrm{NSE}=99.9043 \%$ and IA $=99.9761 \%$ while the linear logarithmic PAR temperature based models with $\mathrm{R}^{2}=74.2 \%, \mathrm{MBE}=0.0111 \mathrm{MJm}^{-2} \mathrm{day}^{-1} \mathrm{RMSE}=0.5837 \mathrm{MJm}^{-2} \mathrm{day}^{-1} \mathrm{MPE}=-$ $0.7278 \mathrm{MJm}^{-2} \mathrm{day}^{-1}, \mathrm{t}-$ test $=0.0631, \mathrm{NSE}=99.4631 \%$ and IA $=99.8650 \%$ was found more suitable for estimating PAR for the location under study. The most suitable PAR sunshine based and temperature based models were compared on the basis of the values of their respective statistical indicators; and it was found that the PAR sunshine based model is more suitable for PAR estimation for the study area. It was observed that the values of PAR are high during the dry season and low during the rainy season; this is expected as high global solar radiation during the dry season may increase the PAR. Based on the measured and estimated PAR models; the minimum values were found in July and August while the maximum values in February, March and November. The descriptive statistical analysis shows that the PAR and all the estimated sunshine based PAR data spread out more to the left of their mean value (negatively skewed). Similarly, they have negative kurtosis which indicates a relatively flat distribution and possibility of platykurtic distribution. The PAR and equation 17a data spread out more to the left of their mean value (negatively skewed), while equation $17 \mathrm{~b}$ and $17 \mathrm{c}$ data spread out more to the right of their mean value (positively skewed). The PAR and all the estimated PAR temperature based data have negative kurtosis which indicates a relatively flat distribution and possibility of platykurtic distribution. The results of this study have clearly revealed that if the global solar radiation data is not available due to the high cost, the PAR sunshine based model proposed in this study can be used for estimating photosynthetically active radiation (PAR) for Akure at any given time of the day and season of the year. Similarly, if the sunshine hours data are not available the PAR temperature based model proposed in this study can be used if temperature data are available. 


\section{ACKNOWLEDGEMENT}

The authors are grateful to the management and staff of the Nigerian Meteorological Agency (NIMET), Oshodi, Lagos for providing all the necessary data used in this present study. The contribution and suggestions of the anonymous reviewers is well appreciated.

\section{REFERENCES}

[1] Wild, M., Gilgen, H., Roesch, A et al., (2005). From dimming to brightening: Decadal changes in solar radiation at Earth's surface. Science, 308(5723): 847-850.

[2] Wild, M (2009). Global dimming and brightening: A review. Journal of Geophysical Research Atmospheres, 114(21): D00D16.

[3] Sun, J. S and Zhou, G. S (2010). Review of advances in measurements and effects of diffuse radiation on terrestrial ecosystem productivity. Chinese Journal of Plant Ecology, 34(4): 452-461. (in Chinese).

[4] McCree, K. J (1972). Test of current definitions of photosynthetically active radiation against leaf photosynthesis data, Agric. Meteorol., 10, 443-453.

[5] Nwokolo, S. C., Ogbulezie, J. C., Toge, C. K and John-Jaja, S. A (2016). Modeling the Influence of Relative Humidity on Photosynthetically Active Radiation from Global Horizontal Irradiation in Six Tropical Ecological Zones in Nigeria. N Y Sci J, 9(11):40-55.

[6] Nwokolo, S. C., Ogbulezie, J. C., Toge, C. K and John-Jaja, S. A (2017). Photosynthetically active radiation estimation and modeling over dif-ferent climatic zones in Nigeria. Journal of Agriculture and Ecology research International,http://sciencedomain.org/journal/37/articles-press.

[7] Prince, S. D (1991). A model of regional primary production for use with coarse resolution satellite data. International Journal of Remote Sensing, vol. 12, no. 6, pp. 1313-1330

[8] Running, S. W., Nemani, R., Glassy, J. M and Thornton, P. E (1999). MODIS Daily Photosynthesis (PSN) and Annual Net PrimaryProduction (NPP) Product (MOD17), Algorithm Theoretical Basis Document University of Montana, Missoula, Mont, USA.

[9] Sasai, T., Ichii, K., Yamaguchi, Y and Nemani, R (2005). Simulating terrestrial carbon fluxes using the new biosphere model integrating eco-physiological and mechanistic approaches using satellite data" (BEAMS)," Journal of Geophysical Research, vol. 110, no. G2.

[10] Zhao, M., Heinsch, F. A., Nemani, R. R and Running, S. W (2005). Improvements of the MODIS terrestrial gross and net primary production global data set, Remote Sensing of Environment, vol. 95, no. 2, pp. 164-176.

[11] Udo, S. O and Aro, T. O (1999). Global PAR related to global solar radiation for central Nigeria. Agricultural and Forest Meteorology, vol. 97, no. 1, pp. 21-31.

[12] Jacovides, C. P., Timvios, F. S., Papaioannou, G., Asimakopoulos, D. N., Theofilou, C. M (2004). Ratio of PAR to broadband solar radiation measured in Cyprus. Agricultural and Forest Meteorology, vol. 121, no. 3-4, pp. 135-140.

[13] Escobedo, J. F., Gomes, E. N., Oliveira, A. P and Soares, J (2009). Modeling hourly and daily fractions of UV, PAR and NIR to global solar radiation under various sky conditions at Botucatu, Brazil, Applied Energy, vol. 86, no. 3, pp. 299-309.

[14] Howell, T. A., Meek, D. W and Hatfield, J. L. (1983). Relationship of photosynthetically active radiation to shortwave radiation in the San Joaquin Valley. Agric For Meteorol, 28:157-175.https://doi.org/10.1016/0002-1571(83)90005-5.

[15] Zhou, Y., Xiang, Y and Luan, L (1996). Climatological estimation of photosynthetically active quantum flux.ActaMeteolSinica, 54(4):447-454.

[16] Papaioannou, G., Nikolidakis, G., Asimakopoulos, D and Retalis, D (1996). Photosynthetically active radiation in Athens.Agric For Meteorol, 81:287-298.https://doi.org/10.1016/0168 1923(95)02290-2. 
[17] Zhang, X., Zhang, Y and Zhao, Y (2000). Measuring and modeling photosynthetically active radiation in Tibetan Plateau during April-October.Agric For Meteorol, 102:207-212. https://doi.org/10.1016/S0168-1923(00)00093-9.

[18] Gonzalez, J. A and Calbo, J (2002). Modeled and measured ratio of PAR to global radiation under cloudless skies. Agric For Meteorol, 110:319-325.https://doi.org/10.1016/S0168 1923(01)00291-X.

[19] Jacovides, C. P., Tymvios, F. S., Asimakopoulos, D. N and Pashiardes, S (2003). Global photosynthetically active radiation and its relation-ship with global solar radiation in the eastern Mediterranean basin.

[20] Finch, D. A, Bailey, W. G, McArthu, L. J. B and Nasitwitwi, M (2004). Photo-synthetically active radiation regimes in a southern African savanna environment. Agric For Meteorol. 122:229-238. https://doi.org/10.1016/j.agrformet.2003.09.015.

[21] Hu, B., Wang, Y. S and Liu, G. R (2007). Measurements and estimations of photosynthetically active radiation in Beijing. Atmospheric Research, 85:361-371. https://doi.org/10.1016/j.atmosres.2007.02.005.

[22] Wang, Q., Kakubari, Y., Kubota, M and Tenhunen, J (2007). Variation of PAR to global solar radiation ratio along altitude gradient in Naeba Mountain.TheorApplClimatol, 87:239-253. https://doi.org/10.1007/s00704-005-0220-6.

[23] Xia, X., Li, Z., Wang, P., Cribb, M., Chen, H and Zhao, Y (2008). Analysis of photosynthetic photon flux density and its parameterization in Northern China.Agric For Meteorol, 148:1101-1108. https://doi.org/10.1016/j.agrformet.2008.02.008.

[24] Li, R., Zhao, L., Ding, Y. J., Wang, S and Ji, G. L (2010). Monthly ratios of PAR to global solar radiation measured at northern Tibetan Plateau, China. Sol Energ, 84:964-973. https://doi.org/10.1016/j.solener.2010.03.005.

[25] Ayeni, A (2011). Malaria Morbidity in Akure, Southwest, Nigeria: A Temporal Observation in a Climate Change Scenario. Trends in Appl. Sci. Res. 6: 488-494.

[26] Balogun, I. A., Debo, A. Z., Ahmed, A. B and Tobi, E. M (2011). Analysis of Urban Expansion and Land Use Changes in Akure, Nigeria, Using Remote Sensing and GIS Techniques. J. Geogr. Phy.Plann. 4(9):533-541.

[27] Barbour, K. M., Oguntoyinbo, J. S., Onyemelukwue, J. O. C and Nwafor, J. C (1982). Nigeria in maps.Hodder and Stonghton, London.

[28] Uluocha, N. O and Ekop, G (2002). Nigeria: Geography. In: History and Cultures of Nigeria up to AD 2000. Lagos: Osuntokun, A., D. Aworawo and F. Masajuw a (Eds). Frankad Publishers, Nigeria. pp. 3-19.

[29] Iqbal, M (1983). An introduction to solar radiation, first ed. Academic Press, New York.

[30] Zekai, S (2008). Solar energy fundamentals and modeling techniques: atmosphere, Environment, climate change and renewable energy, first ed. Springer, London.

[31] Moon, P (1940). Proposed standard solar radiation curves for engineering use. J. Franklin Inst. 230:583-618.

[32] Williams, J. G (1976). Small variation in the photo synthetically active radiation of solar radiation on clear days. J. Arch. Meteor. Geophs.Bioclim. 33:89-98.

[33] Meek, D. W., Hatfield, J. L., Howell, J. L., Idso, T. A and Reginato, S. E. R. J (1984). A generalized relationship between photosynthecally active radiation and solar radiation.Agron. J. 76:939-945.

[34] Tsubo, M and Walker, S (2005). Relationships between photo synthetically active radiation and clearness index at Bloemfontein, South Africa. Theor. Appl. Climatol. 80:17-25. DOI: 10.007/s00704-0080-5

[35] Monteith, J. L (1990). Unsworth M. Principle of environmental physics.Second ed. Edward Arnold, London.

[36] Gates, D. M (1980). Biophysical ecology. Third ed. Springer-Verlag, New York

[37] El-Sebaii, A and Trabea, A (2005). Estimation of Global Solar Radiation on Horizontal Surfaces Over Egypt, Egypt. J. Solids, 28 (1), 163-175. 
[38] Bevington, P. R (1969). Data reduction and error analysis for the physical sciences, first ed. McGraw Hill Book Co., New York.

[39] Chen, R., Ersi, K., Yang, J., Lu, S and Zhao, W (2004). Validation of five global radiation Models with measured daily data in China. Energy Conversion and Management.,45, 1759-1769.

[40] Merges, H. O., Ertekin, C and Sonmete, M. H (2006). Evaluation of global solar radiation Models for Konya, Turkey. Energy Conversion and Management.,47, 3149-3173

[41] Akpootu, D. O and Iliyasu, M. I (2015a). A Comparative Study of some Meteorological Parameters for Predicting Global Solar Radiation in Kano, Nigeria Based on Three Variable Correlations. Advances in Physics Theories and Applications. Vol.49: $1-9$.

[42] Akpootu, D. O and Iliyasu, M. I (2015b). The Impact of some Meteorological Variables on the Estimation of Global Solar Radiation in Kano, North Western, Nigeria.Journal of Natural Sciences Research. Vol.5, No.22: 1 - 13.

[43] Akpootu, D. O., Iliyasu, M. I., Mustapha, W., Aruna, S and Yusuf, S. O (2017). The Influence of Meteorological Parameters on Atmospheric Visibility over Ikeja, Nigeria.Archives of Current Research International.,9(3): 1-12.

[44] Hejase, H. A. N and Assi, A. H (2011). Time-Series Regression Model for Prediction of Monthly and Daily Average Global Solar Radiation in Al Ain City-UAE. Proceedings of the Global Conference on Global Warming held on 11 - 14 July, 2011 , Lisbon, Portugal. Pp $1-11$.

[45] Etuk, S. E., Okechukwu, E. A and Nwokolo, C. S (2016). Modelling and Estimating Photosynthetically Active Radiation from Measured Global Solar Radiation at Calabar, Nigeria. Physical Science International Journal., 12(2): 1 - 12. 